\title{
Is analysis of otolith microstructure a valid method for investigating early life history of Western Baltic cod?
}

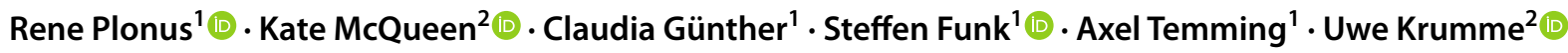

Received: 7 September 2020 / Accepted: 15 January 2021 / Published online: 11 February 2021

(c) The Author(s) 2021

\begin{abstract}
Daily formation of fish otolith micro-increments is frequently assumed, however applying inferences about timing of life history events and formation of otolith macro-structures requires further validation of the periodicity of micro-increment formation. We analysed micro-increments from Western Baltic cod (WBC, Gadus morhua) otoliths marked with tetracycline-hydrochloride as part of an age validation study to test the assumption of daily formation of micro-increments. We found that the number of counted micro-increments consistently underestimated the age of cod aged 1 and older. Time at liberty was also underestimated, especially for fish at liberty during winter. In contrast, micro-increment counts of otoliths from wild-caught young-of-the-year (YOY) cod could be used to realistically estimate timing of hatch and translucent zone formation. Under ambient conditions, settlement did not correspond to any visible pattern within the otoliths, but could be inferred from the prey switch observed from stomach content analyses. We therefore conclude that micro-increments can be assumed to form on a daily basis until the first winter, and can therefore be used to investigate early life history of YOY WBC. However, the periodicity of micro-increment formation appears to vary seasonally in older individuals, with the number of micro-increments formed during the winter period being particularly low.
\end{abstract}

\section{Introduction}

Micro-increments are visible structures within fish otoliths that often form on a daily basis (Panella 1971), and have been widely used to study the early life history of juvenile fish. For example, micro-increment counts have proven useful for estimating age (e.g.,Geffen 1995; Hüssy et al. 2003a; Neat et al. 2008) and fitting growth curves of juvenile fish (e.g., Bolz and Lough 1988). Interpretation of changes in the microstructure of fish otoliths has been used to estimate timing of life history events, including settlement or metamorphosis (e.g.,Morales-Nin 1987; Bolz and Lough 1988;

Responsible Editor: E. Hunter.

Reviewed by undisclosed experts.

Rene Plonus

rene-marcel.plonus@uni-hamburg.de

1 Institute of Marine Ecosystem and Fishery Science, Faculty of Mathematics, Informatics and Natural Sciences, University of Hamburg, Olbersweg 24, 22767 Hamburg, Germany

2 Thünen Institute of Baltic Sea Fisheries, Alter Hafen Süd 2, 18069 Rostock, Germany
Oeberst and Böttcher 1998; Hüssy et al. 2003b). Due to the assumed daily periodicity of micro-increments, analysis of these structures has also been used to validate other methods of age estimation, such as the interpretation of otolith macro-structures (e.g.,Lang et al. 1996; Waldron and Kerstan 2001).

Most investigations using microstructural otolith analysis assume that these increments form with a reliable daily periodicity. However, given the variety in fish species and life cycles, a generalization of daily increment formation can be challenged. Deviations from daily micro-increment formation are common in older fish (Beamish and McFarlane 1987; Ralston and Williams 1989; Wright et al. 1990), but may also occur in younger fish (Campana and Moksness 1991; Folkvord et al. 2000; Baumann et al. 2005). Therefore, the periodicity of micro-increments should be validated before they are used to draw inferences about age and life history of individuals (Campana and Neilson 1985). A variety of methods are available to validate the periodicity of otolith micro-increments, and usually involve inducing a mark on the otolith to act as a "time-stamp", for example through temperature shock (e.g., Neat et al. 2008), or the introduction of a calcium binding chemical (Campana 2001). However, attempts to validate regular daily 
increment formation have often been neglected (Beamish and McFarlane 1983; Campana 2001). So far, no attempt has been made to validate daily increment formation of Atlantic cod using mark-recapture material (Vitale et al. 2019) and laboratory experiments addressing this issue have never exceeded an age of 160 days (e.g.,Campana and Moksness 1991; Geffen 1995; Hüssy et al. 2003a; Narimatsij et al. 2009; Campana 2011).

Two genetically distinct cod (Gadus morhua) stocks inhabit the Baltic Sea, the Western and Eastern Baltic cod stocks. The Western Baltic cod (WBC) is the smaller of the two stocks, and inhabits the relatively shallow and more saline western Baltic Sea. Baltic cod are ecologically important, as one of the main piscivorous predators in the species-poor Baltic Sea (Link et al. 2008). North-Atlantic cod also have socio-economic importance (Kurlansky 1997), especially for small-scale fisheries in the western Baltic Sea (Delaney 2007) and recreational fishers (Strehlow et al. 2012). The recruitment to the WBC stock has been variable since at least the 1980s (ICES 2020). Since 2015, the annual recruitment has been at a record low, with the exception of a relatively strong year class in 2016 (ICES 2020). Negative effects of ocean warming on recruitment are evident (Stiasny et al. 2016; Voss et al. 2019), but the mechanisms currently driving the low recruitment are not fully understood. Analysis of otolith micro-increments has been used to study recruitment variability in other cod stocks (Campana 1996) and may therefore be an appropriate method to explore the drivers of variable year class strength in WBC.

Relationships between features of otolith micro-structure in Baltic cod otoliths and key life history events have been described in previous studies. Hatching induces a hatch check (see Kalish et al. (1995) for terminology definitions), followed by a core area containing an average of 45 micro-increments that can be difficult to interpret (Oeberst and Böttcher 1998; Huwer 2009). This core area is delimited by an accessory growth centre (AGC, Oeberst and Böttcher 1998). Pelagic cod juveniles then go through a settlement period, a transition that has been related to a decrease in the width of otolith microincrements in Eastern Baltic cod (EBC, Hüssy et al. 2003b). It has been suggested that settlement can cause a translucent zone to form in the otoliths of WBC (Rehberg-Haas et al. 2012). Although the daily periodicity of micro-increments in EBC juveniles has been indirectly validated (Hüssy et al. 2003a), the periodicity of WBC otolith micro-increments has not been investigated in detail. The daily periodicity of microincrements in juvenile EBC otoliths appears valid only during early life, as otoliths of adults are reported to stop forming micro-increments during the winter (Hüssy et al. 2010). In contrast, a cessation in micro-increment formation in WBC otoliths over the winter period was not identified in another study published at around the same time (Rehberg-Haas et al. 2012). However, comparison of estimated ages of juvenile
WBC from micro-structural analysis of otoliths (Rehberg-Haas et al. 2012) with results of an age validation study (McQueen et al. 2019) indicates that micro-structural analysis of WBC otoliths can under-estimate the age of individuals, despite the constant formation of micro-increments reported by RehbergHaas et al. (2012). Furthermore, the appearance of the macroincrements of WBC and EBC otolith differ markedly (Stötera and Krumme 2016), with EBC otoliths lacking well-defined zones, likely due to a life in a deeper, permanently stratified environment (Hüssy et al. 2003a) with the unusual overlap of temperature and food availability cycles (Hüssy 2010). Given the differences in environmental experience and otolith appearance between the two cod stocks, we cannot assume that the periodicity of WBC micro-increments will necessarily be similar to those of EBC. Therefore, a more thorough investigation of the periodicity of micro-increment analysis of WBC otoliths is required before this method can reliably be applied to the analysis of their early life ecology.

The objective of this study was to assess the periodicity of WBC otolith micro-increments which requires a precise and accurate microstructural analysis. Precision of the method was assessed through repeated interpretation of otoliths from young-of-the-year (YOY) WBC from two consecutive year classes. Accuracy of the method was assessed through analysis of otoliths marked with tetracycline-hydrochloride, from recaptured cod tagged as part of an age validation study. The known days at liberty were compared with the counted micro-increments between release and recapture, and the ages estimated through validated methods were compared with the total number of counted increments. Analysis of otolith micro-increments was also used to estimate the timing of known life history events from the otoliths of YOY fish, to corroborate the accuracy of this method. As ambient temperature and feeding conditions are major drivers of otolith opacity and growth, we also investigated the relationships between these two environmental variables and patterns in otolith microstructure and opacity observed during otolith micro-increment counts. The results can be used as a foundation for future analyses using otolith microstructure to explore early life history of WBC.

\section{Materials and methods}

\section{Study area and sampling}

Juvenile cod originated from two sources in ICES subdivision 22 in the western Baltic Sea (Fig. 1): (i) Cod from the Mecklenburg Bight (ICES rectangle 37G1) were collected from commercial uncovered pound nets distributed along the south coast of Fehmarn $(\mathrm{F})$ and the adjacent mainland during autumn of 2015 and 2016 (Table 1). The catch chambers of the pound nets were located at about $5 \mathrm{~m}$ water depth (for 
more details about the pound net sampling see McQueen et al. (2019)). Otoliths for cod $<200 \mathrm{~mm}$ total length were selected for analysis (Supplementary Fig. S2), to ensure that only age-0 fish (i.e., YOY) were included (McQueen et al. 2019). These pound nets were also the source of juvenile cod marked with tetracycline-hydrochloride for an age-validation mark-recapture experiment (Krumme et al. 2020, Table 2). (ii) Cod from Kiel Bight (ICES rectangle 37G0) were collected from trawl catches at the Stollergrund ( $\mathrm{S}$, otter board

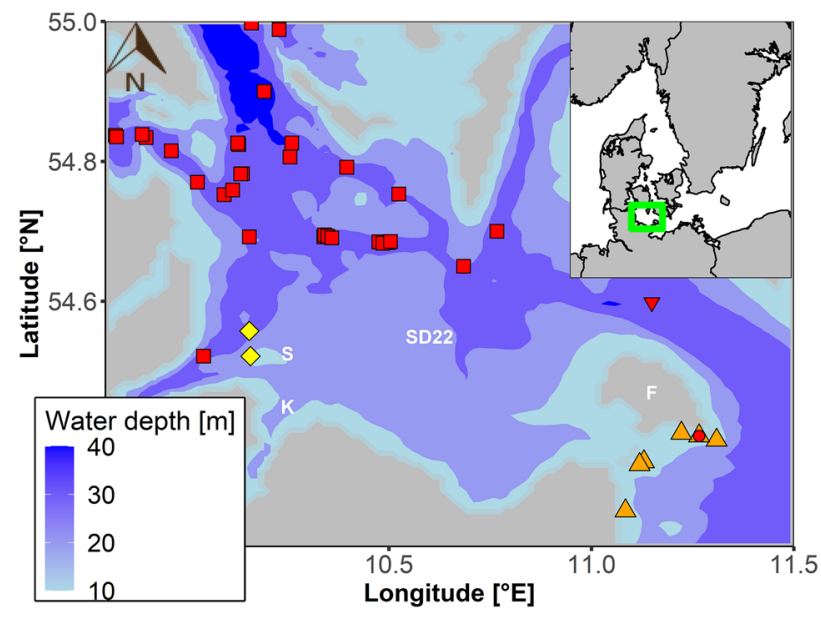

Fig. 1 Sampling sites in the western Baltic Sea. Yellow squares: location of young-fish trawls (August, October) near Stollergrund (S); orange triangles: location of pound nets near Fehmarn $(\mathrm{F})$; red dot: location of temperature logger at pound net; red squares: stations for temperature measurements downloaded from the ICES website; red triangle: Temperature buoy Fehmarn belt by the BSH, K: Kiel Bight, SD22: ICES Subdivision young-fish trawl, mesh size in the codend: $4 \mathrm{~mm}$ between knots) conducted between 5-20 m water depth in August and October 2016 (Table 1). The Stollergrund samples were used for stomach content analyses as further evidence for the settlement period of juvenile cod.

The Stollergrund is an abrasion platform just north of the Kiel Bight and is relatively exposed compared to the southern coast of Fehmarn, where seagrass beds provide shelter for juvenile cod (Krumme et al. 2020). YOY cod in the Kiel Bight were likely spawned in the small Belt (Thurow 1963), while juveniles at Fehmarn were probably spawned in the Fehmarn Belt or Mecklenburg Bight (Bagge et al. 1994; Brander 2005). Therefore, our samples represent juveniles from two of the main cod spawning areas in the western Baltic Sea.

All young cod were frozen at $-20^{\circ} \mathrm{C}$ and later thawed before measuring the total length (TL, to the nearest $\mathrm{cm}$ below) and wet weight (WW, to the nearest $\mathrm{g}$ ). Both sagittal otoliths were removed, weighed to the nearest $0.01 \mathrm{mg}$ (otolith weight $=\mathrm{OW}$ ) and stored in paper envelopes for further analyses.

\section{Water temperature}

To relate temporal changes in otolith microstructure to changes in water temperature, water temperature data from several sources were used. A HOBO Pro water temperature logger (Onset) fixed to a pillar of a pound net at $2 \mathrm{~m}$ water depth (Fig. 1) collected sea surface temperatures on the south coast of Fehmarn from April 2015 to December 2016 at least once every 6 hours. A daily mean was used for the analyses.
Table 1 Overview of the number of analysed Baltic cod otoliths (available otoliths in brackets) from the two sampling campaigns (sampled otoliths) and a tag-recapture program (marked otoliths)

\begin{tabular}{|c|c|c|c|c|c|}
\hline \multirow[t]{2}{*}{ Year } & \multirow[t]{2}{*}{ Sampling month } & \multicolumn{4}{|c|}{ Number of otoliths } \\
\hline & & $\begin{array}{l}\text { Marked per } \\
\text { month }\end{array}$ & Marked per year & Sampled per month & Sampled per year \\
\hline \multirow[t]{2}{*}{2014} & $\mathrm{May}_{\mathrm{F}, \mathrm{PN}}$ & $1(1)$ & $2(2)$ & $0(0)$ & $0(0)$ \\
\hline & November $_{\mathrm{F}, \mathrm{PN}}$ & $1(1)$ & & $0(0)$ & \\
\hline \multirow[t]{4}{*}{2015} & June $_{F, P N}$ & $4(6)$ & $7(9)$ & $0(0)$ & $39(97)$ \\
\hline & September $_{\mathrm{F}, \mathrm{PN}}$ & $2(2)$ & & $1(22)$ & \\
\hline & October $_{\mathrm{F}, \mathrm{PN}}$ & $0(0)$ & & $17(31)$ & \\
\hline & November $_{F, P N}$ & $1(1)$ & & $21(44)$ & \\
\hline \multirow[t]{5}{*}{2016} & January $_{\mathrm{F}, \mathrm{PN}}$ & $1(1)$ & $2(2)$ & $0(0)$ & $51(89)$ \\
\hline & April $_{\mathrm{F}, \mathrm{PN}}$ & $1(1)$ & & $0(0)$ & \\
\hline & August $_{S, Y F T}$ & $0(0)$ & & $18(45)$ & \\
\hline & October $_{\mathrm{S}, \mathrm{YFT}}$ & $0(0)$ & & $14(19)$ & \\
\hline & November $_{F, P N}$ & $0(0)$ & & $19(25)$ & \\
\hline \multirow[t]{2}{*}{2017} & April $_{\mathrm{F}, \mathrm{PN}}$ & $1(1)$ & $2(2)$ & $0(0)$ & $0(0)$ \\
\hline & May $_{F, P N}$ & $1(1)$ & & $0(0)$ & \\
\hline
\end{tabular}

Number of analysed YOY cod otoliths: 90 (from 186 available otoliths)

$P N$ pound net; $Y F T$ young fish trawl; $F$ Fehmarn; $S$ Stollergrund 


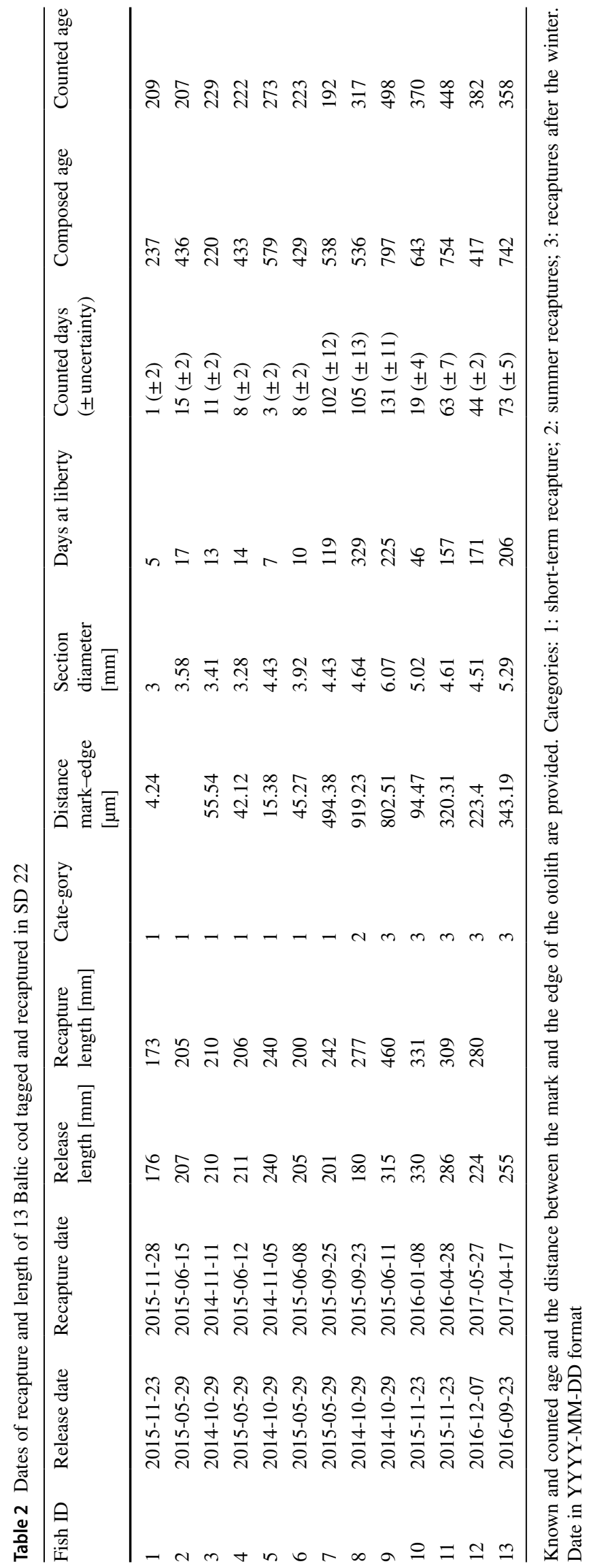


Water temperature data recorded at several depths in the water column from a measurement buoy in the nearby Fehmarn Belt (Fig. 1) were provided by the Federal Maritime and Hydrographic Agency (Bundesamt für Seeschifffahrt und Hydrographie (BSH)) from the DOD (Deutsches Ozeanografisches Datenzentrum).

For the Kiel Bight area, water temperature data from the ICES oceanographic database (ICES 2014) were used. Half-monthly average water temperatures were calculated using all stations deeper than $25 \mathrm{~m}$ (Fig. 1). Since water temperatures were measured at different depths at some stations, measurements were grouped into a $2.5 \mathrm{~m}$ surface layer $(0-2.5 \mathrm{~m})$ and $5 \mathrm{~m}$ water layers thereafter (2.6-7.5 m,...,37.6-42.5).

\section{Preparation of otoliths and analysis of microstructure}

\section{Preparation of otoliths}

An overview image of each otolith was taken with a highdefinition camera (Leica ${ }^{\circledR}$ DC300; $3132 \times 2328$ Pixel) through a binocular stereomicroscope (Olympus SZH Zoom Stereo Microscope). Based on the overview images, the distance between the core and the transition from the opaque to the first translucent zone (TZ) was measured to the nearest $10 \mu \mathrm{m}$.

Otoliths were prepared using the "embed and polish method" described in Stevenson and Campana (1992) and increments were counted along a dorso-ventral axis (Supplementary Fig. 3). Ninety-eight otoliths were damaged during the preparation process and could not be used, resulting in a total of 103 analysed otoliths (Table 1).

\section{Imaging of otolith micro- and macrostructures}

Images of the polished otoliths were taken along an axis from the core (left) to the edge (right) with a high-definition camera (Leica® DC300; $3132 \times 2328$ Pixel) under a binocular stereomicroscope (Olympus VANOS-S) in black and white with transmitted light and analysed with an image analysis software (ImagePRO 6.0). Given the relatively large size of cod otoliths, it was not possible to take an image of the whole otolith at the highest intended magnification of $400 \times$. Several overlapping images were necessary to cover a transect from the core to the edge. From each image, multiple replicates in different focal planes were taken to improve the interpretation of the otolith microstructures. All the replicates were used to generate one increment count for each image. The last replicate of a given image was always in the same focal plane as the first replicate of the next image. Depending on the individual images, 4-12 replicates were taken. Each new image started to the right of the previous image. Noticeable marks visible both on the right edge of the previous and the left edge of the next image were used to ensure overlap between consecutive images (Supplementary Fig. S4). For each sequence of replicates an integrated quality-flag for visibility of otolith micro-increments throughout the otolith image was assigned using a scale from 1 (clearly visible) to 4 (partially invisible; Supplementary Table S1).

\section{Counting and measurement of otolith micro-increments}

From the photographs in ImagePRO, micro-increments were counted and each increment width (IW) was measured (to the nearest $0.1 \mu \mathrm{m}$ ) along either the dorsal or ventral axis. All increment counts were executed by the first author. The last increment counted was assumed to be incomplete and was excluded from the analysis.

For each otolith, the hatch check (HC) was identified (Supplementary Fig. S5) and measured (to the nearest $0.1 \mu \mathrm{m})$. In 39 of 90 YOY cod otoliths, the hatch check could not be reliably identified.

Interpretation of micro-increments within the core area (i.e., the area within the AGC, Supplementary Fig. S5) was performed with reference to the description of Huwer (2009), which states that the hatch check is surrounded by approximately 20 fainter initial increments. Subsequent increments increase in width and form substructures. After the AGC, increments again appear considerably broader and more distinct.

In the same 39 otoliths (see above), it was not possible to obtain a clear image of the core area and the increments could not be reliably counted. Equation (1) established a relationship between the otolith radius (OR) and the increment number $(n)$, by summing the increment widths (IW) of the increments $1-n$ and the width of the hatch check (HC):

$\mathrm{OR}_{n}=\mathrm{HC}+\sum_{i=1}^{n} \mathrm{IW}$

Measurements taken on the 51 otoliths with interpretable core areas were used to estimate a mean increment number ( $n$ ) for each otolith radius (OR). The OR from the core to the first visible increment of each of the 39 otoliths lacking clear images of the core was used to estimate the number of increments within these unreadable regions, using Eq. (1). A detailed description of the efforts undertaken to investigate the precision of the method is given in the Supplementary material (S1 Precision of micro increments counts). 


\section{Accuracy of micro-increment counts}

A total of 13 tetracycline-marked recaptured juvenile cod from an age-validation experiment were available (Krumme et al. 2020, Table 2). The otoliths were processed using the "embed and polish" method, and micro-increments were counted and measured along the dorso-ventral axis, as with the YOY otoliths. Additionally, a picture under a UV-light filter (Olympus U-MNV filter cube: barrier filter: $455 \mathrm{~nm}$, excitation filter: $400-410 \mathrm{~nm}$, dichroic mirror: $455 \mathrm{~nm}$ ) was taken to visualize the location of the tetracycline mark (Supplementary Fig. S6). The distance between the tetracycline mark and the edge of the otolith was measured and the number of increments within this region was calculated (i.e., number of days between tagging and recapture).

The composed age (in years: Age $_{\text {years }}$ ) of recaptured individuals was estimated following the age reading guide of Krumme et al. (2020) and compared to the total number of counted micro-increments. A composed age in days $\left(\mathrm{Age}_{\mathrm{days}}\right)$ for each fish was calculated as

$\mathrm{Age}_{\text {days }}=$ Days $_{\mathrm{YO}}+\left(\right.$ Age $\left._{\text {years }}-1\right) \times 365+$ Days $_{\mathrm{YC}}$

The "birthday" assigned artificially to all WBC for standard age reading is $1 \mathrm{st}$ January. Days ${ }_{\mathrm{Y} 0}$ represents the age at the first birthday of any individual and was specified as 270 , since day 95 of the year was the mean estimated hatch day for juvenile cod in 2015 and 2016 (see sections on "Estimation of hatch period"). Age years -1 was the number of intermediate years between the year of birth (Y0) and the year of catch (YC). Days ${ }_{\mathrm{YC}}$ is the number of days, which had passed during YC. For illustrative purposes, the $\mathrm{Age}_{\text {days }}$ for one of the tagged cod included in this study, recaptured on 11th June as age-2, would be calculated as:

$\mathrm{Age}_{\text {days }}=270+(2-1) \times 365+162=797$

We additionally used Eq. (2) to estimate the composed age of 715 small cod (110-390 mm TL) captured in the pound nets ( $n=626$ year-round in 2015, $n=89$ from January to June 2016), which were otherwise not directly used in this study, but which were used in a previous age validation study of juvenile WBC (McQueen et al. 2019). The relationship between length at capture and composed age of these otoliths was visually compared to the relationship between length at capture and number of counted increments of all analysed otoliths.

\section{Estimation of hatch period}

To estimate the hatch period of juvenile WBC, the hatch day of the YOY cod was estimated as the catch day minus the number of counted micro-increments. A possible hatch period (multiple days) for each individual was estimated to account for the uncertainty in micro-increment counts (see Supplementary Material S1).

Each month was divided into thirds (e.g., early: days 1-10, mid: days 11-20 and late: days 21-31) and all possible hatch events within each third were counted. The number of hatch events per third was divided by the total number of hatch events to estimate the probability distribution of hatch events across the entire hatch period.

\section{Back-calculation of weight and length}

To estimate the length at which TZ formation occurred, a relationship between TL (of juvenile and young adult cod (measured to the nearest $\mathrm{cm}$ below) covering a length range of $6-46 \mathrm{~cm}$ ) and OR was established by fitting a linear model (with slope $b$ and intercept $a$ ):

$\ln (\mathrm{TL})=a_{\mathrm{TL}}+b_{\mathrm{TL}} \times \ln (\mathrm{OR})$

The parameters were fit to the data using the $1 \mathrm{~m}$-function (RCoreTeam 2020). To account for individual variability in growth, cod total lengths at TZ formation as modelled by Eq. (3) were adjusted by assuming a proportional relationship between fish size and otolith size over time, as in Hüssy et al. (2003b) or Bolle et al. (2004):

$\mathrm{TL}_{i}=\mathrm{TL}_{n} \times \frac{\mathrm{MV}_{i}}{\mathrm{MV}_{n}}$

This proportionality method assumes that for an individual with $\mathrm{n}$ increments, total length at increment $i\left(\mathrm{TL}_{i}\right)$ is proportional to total length at capture $\left(\mathrm{TL}_{n}\right)$, in the same ratio as the modelled value at increment $i\left(\mathrm{MV}_{i}\right)$ is proportional to the modelled value at capture $\left(\mathrm{MV}_{n}\right)$.

To investigate the relationship between the otolith opacity (a potential TZ) and ambient water temperatures during the whole growth period of each fish from larval to juvenile stage, a power function was used to establish a relationship between wet weight (WW) and total length (TL) and to calculate weight-at-age:

$\mathrm{WW}=a_{\mathrm{WW}} \times \mathrm{TL}^{b_{\mathrm{wW}}}$

$a_{\mathrm{WW}}$ and $b_{\mathrm{WW}}$ were estimated with the nls-function (RCoreTeam 2020). In the same way as for length-at-age, Eq. (4) was used to account for individual variability, by exchanging TL with WW in Eq. (4). The optimal growth temperatures $\left(T_{\mathrm{opt.G}}\right)$ were calculated using a function of fish wet weight (WW) by Björnsson (2001) for Icelandic cod:

$T_{\text {opt.G }}=18.28-1.43 \times \ln (W W)$ 
All analyses were carried out with the statistical package R (2017. The R Foundation for Statistical Computing; Version 3.4.0).

\section{Settlement period inferred from stomach content analyses}

To estimate settlement timing, stomach contents of 110 YOY cod caught in Kiel Bight between June and October in 2016 by trawl were analysed (Supplementary Table S3). During settlement, juvenile cod switch from a diet of pelagic prey to a diet of demersal prey and this prey switch should therefore be detectable from stomach content analysis. A detailed description of the stomach content analyses is provided in the supplementary material (S2 Stomach content analysis).

The settlement process was assumed to start at a TL where the amount of planktonic prey present in the stomach contents was $<100 \%$ for the first time. Settlement was assumed to be completed as soon as the amount of planktonic prey no longer exceeded $0 \%$.

For each fish, stomach fullness indices $\left(\mathrm{SFI}=\mathrm{W}_{\mathrm{FS}} /\right.$ $\mathrm{W}_{\mathrm{G}} \times 100$ ) were calculated. Age information was not available for all fish from the stomach content analyses. Thus, for each otolith radius a mean total fish length was calculated using Eq. (3). Mean increment width was then calculated for each fish length, using the relationship between OR and IW described by Eq. (1). A mean otolith increment width was calculated for each fish used for stomach content analysis, using measured length at capture. Thus, otolith increment width could be linked to quantity of food consumed by fish length.

\section{Results}

\section{Water temperature}

Half monthly average water temperature in the Kiel Bight (5 m depth) ranged from $2.5^{\circ} \mathrm{C}$ in January to $19.6{ }^{\circ} \mathrm{C}$ in July (mean: $11^{\circ} \mathrm{C}$ ) in 2016 . Water temperatures measured in the Fehmarn Belt (6 m depth) and with a temperature logger located at the pound nets ( $2 \mathrm{~m}$ depth) in $2016 \mathrm{had}$ a similar range and pattern. Water temperatures measured in the Fehmarn Belt and at the pound nets in 2015 were slightly lower compared to water temperatures in the same region in 2016 but followed the same pattern (Supplementary Fig. S7). In both years, temperatures exceeded $15^{\circ} \mathrm{C}$ between June and October in shallow waters whereas the temperature peak occurred later and was lower at $25 \mathrm{~m}$ depth (Supplementary Fig. S7).

\section{Micro-increment counting and measurement}

The numbers of increments counted within the YOY otoliths ranged from 101 to 275 with uncertainty increasing with age. The average uncertainty was ten increments. The average IW per sampling period remained relatively stable throughout February and March, increased throughout April to June, remained stable until August, and decreased from August to November (Fig. 2a).

\section{Accuracy of micro-increment counts}

\section{Recaptures of chemically marked cod}

The accuracy of micro-increment counts of marked recaptures was low but differed remarkably with times at liberty and the time period spent in liberty. Three distinct categories were observed according to the times at liberty: category 1 consisted of individuals that were recaptured within 20 days of release $(n=6)$; category 2 contained one individual recaptured after a longer period (119 days) within the same year $(n=1)$ and category 3 comprised cod recaptured in the year after release ( $n=6$, Table 2$)$. The mean accuracy of microincrement counts for category 1 and 2 was $66 \%( \pm 26 \%$ SD) while it was $39 \%( \pm 11 \% \mathrm{SD})$ in category 3 .

In category 1 and 2, differences between known and counted days at liberty exceeded the uncertainty in microincrement counts in 4 out of 7 cases by 2, 2, 4 and 5 increments. In contrast, in category 3 , after considering the uncertainty of the counts, the counted number of increments underestimated the known days at liberty by 23-211 days (Fig. 3).

According to the composed age estimated using the age reading guide, two individuals were recaptured at age 0 . Both belonged to category 1 . The other 11 individuals were age 1 (8) or age 2 (3) at recapture and, regardless of the accuracy, micro-increment counts always underestimated the composed age. The overall increment counts (i.e., the whole transect involving both the parts before and after the tetracycline mark) underestimated the composed age by 206-384 days in 10 out of the 11 older individuals, even when the number of counted increments after the mark closely agreed with the number of days spent at liberty (i.e., difference < uncertainty, 3 cases, Table 2). Underestimation of the composed age of the $11^{\text {th }}$ individual was 35 days (Fig. 4). For the age 0 cod, the counted age matched closely with the composed age (i.e., the difference between counted and composed age was less than the SD of the mean hatch day). The relationship between composed age and total length resembled a logarithmic growth curve whereas the relationship between the counted micro-increments and total length was linear (Fig. 4). 


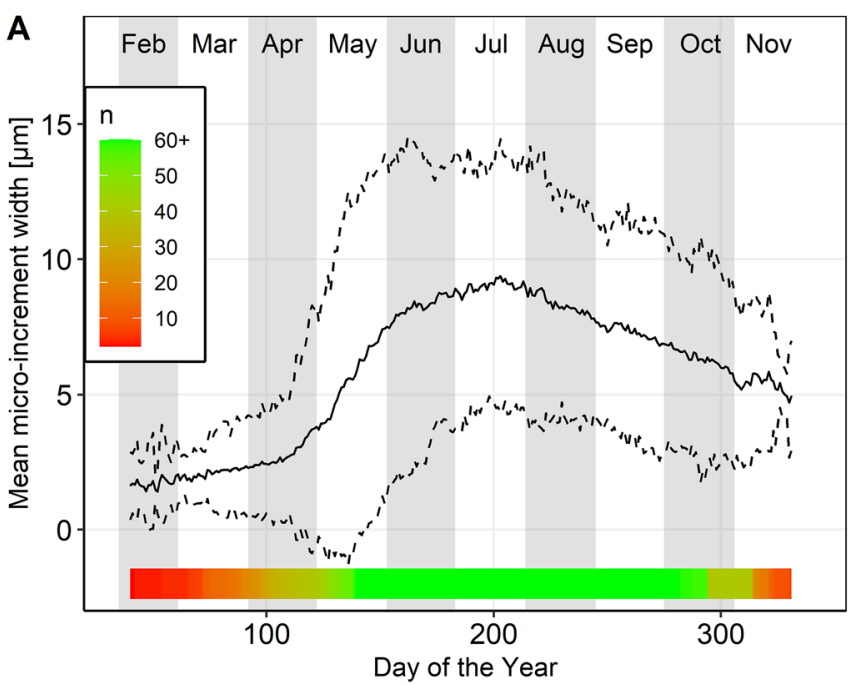

Fig. 2 a Relationship between mean micro-increment width $[\mu \mathrm{m}]$ for $N=90$ analysed YOY cod and the Julian day [DOY]. Dashed lines: show the $95 \%$ confidence intervals. $n$ number of micro-increments represented by the mean. b Difference between the ambient $\left(T_{\text {amb }}\right)$ and the optimal growth temperature $\left(T_{\mathrm{opt}}\right)$ of juvenile cod from the

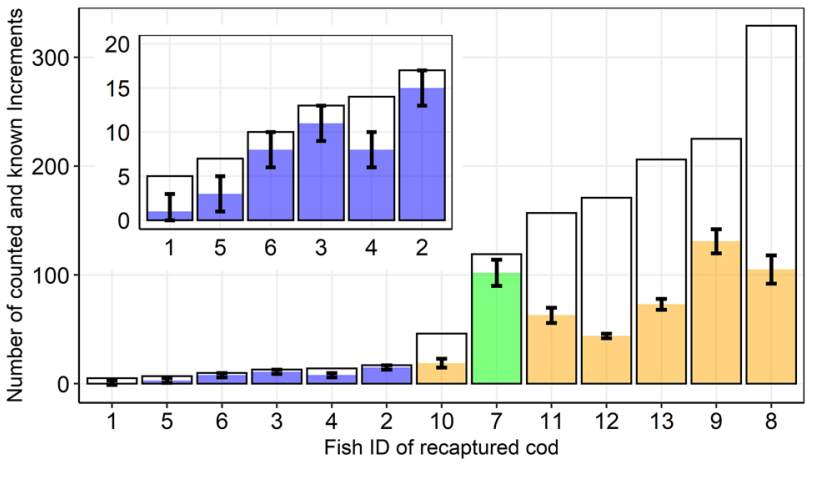

Increments $\square$ known $\square$ Cat. $1 \square$ Cat. $2 \square$ Cat. 3

Fig. 3 Number of counted increments for the period between release and recapture of chemically marked juvenile WBC to assess the accuracy of micro-increment counts. Total bar: known days at liberty; colored: counted increments; error bar: uncertainty in the number of counted increments between the mark and the edge (see Table 2). Categories: 1: short-term recapture; 2: summer recaptures; 3: recaptures after the winter

\section{Hatch date distribution}

In 2015 and 2016, hatching occurred from February to June and from January to May, respectively. Peak hatching occurred during late March, both in 2015 and 2016 (Fig. 5). In 2016, 2 cod were clearly separated from the other 49 YOY cod by hatch date (27th June and 2nd July).
B

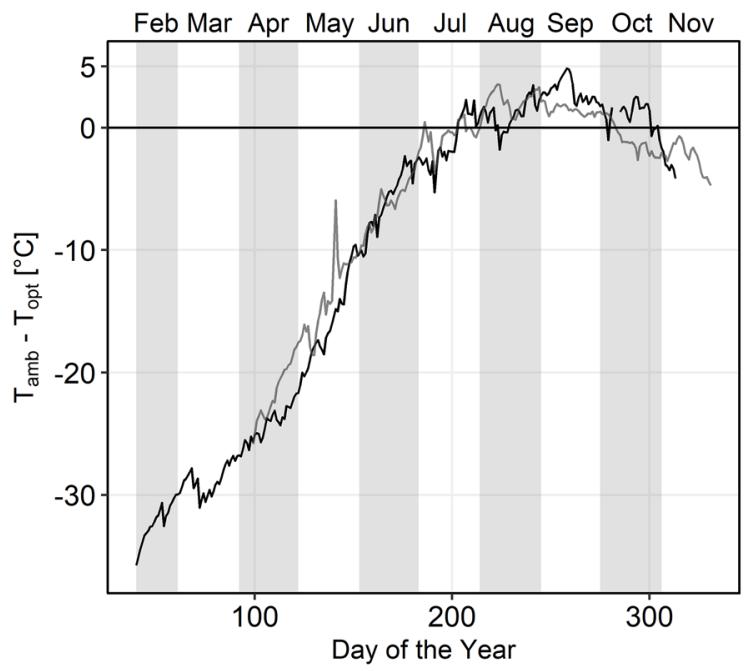

western Baltic Sea in 2015 (grey line) and 2016 (black line). $T_{\mathrm{amb}}$ : temperatures measured at pound net at Fehmarn in $2 \mathrm{~m}$ depth. $T_{\mathrm{opt}}$ : calculated with mean fish weight using the relation of Björnsson (2001). Negative values are lower than optimum ambient temperatures; positive values are above optimum ambient temperatures

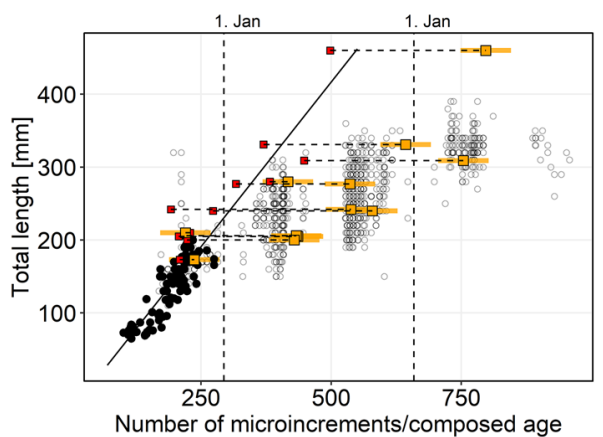

Fig. 4 Individual total length and age (days) of $n=818$ cod otoliths from the western Baltic Sea (SD22). Filled circles: counted microincrements of YOY cod $(n=90)$; open circles: composed ages of small cod captured in pound nets in 2015 and 2016, $n=715$; red squares: counted number of micro-increments of chemically marked recaptures $(n=13)$; orange squares with error bars: composed ages of otoliths from the same chemically marked recaptures $\pm \mathrm{CI}$ of the mean hatch day for 2015 and 2016 (48.5 days), solid line: length-agerelationship for cod with counted ages (black dots + red squares). Vertical dashed line: start of a new calendar year

\section{Settlement period inferred from stomach content analysis}

Timing of prey switch inferred from stomach content analysis indicated that settlement of juvenile WBC sampled from the Stollergrund in 2016 took place in July at an age of 90-120 days. Settlement was initiated at a TL of $46 \mathrm{~mm}$ and completed at a TL of $73 \mathrm{~mm}$ (Fig. 6). 


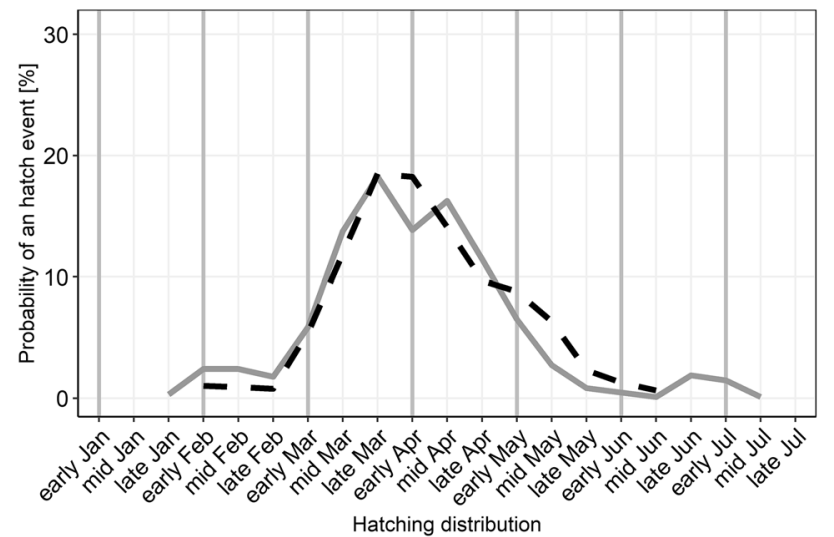

Fig. 5 Distribution of estimated hatch events of juvenile WBC in 2015 (black dashed, $n=39$ ) and 2016 (grey solid, $n=51$ ) as probability for an individual to hatch in a certain period. Each month was divided in thirds of $\sim 10$ days (early: 1-10; mid: 11-20; late: $21-31$ )

Assuming that the length at settlement was constant between years and sampling areas, the estimated age, otolith growth and date of settlement was similar for the YOY cod sampled from Fehmarn in 2015 and 2016 (Fig. 6). Investigation into individual micro-increment measurements of the YOY WBC from Fehmarn revealed no general pattern such as decreased increment widths in relation to the presumed period of settlement and prey shift.

The SFI of cod collected from Stollergrund steadily decreased before the period of settlement. Towards the end of the settlement period and after the observed prey shift from planktonic to benthic prey organisms (dotted line in Fig. 7b) SFI started to increase until a total fish length of 90-100 mm, before it decreased again. In contrast, the estimated mean otolith increment width increased rapidly to a maximum at a total fish length around $30 \mathrm{~mm}$, followed by a steady decrease (Fig. 7a).

\section{Timing of translucent zone formation}

No obvious relationship between the formation of the first $\mathrm{TZ}$ and age or back-calculated length was observed. Despite similar hatch dates, TZ formation started earlier (Fig. 6a, b) and at a smaller fish size (Fig. 6c) in 2015 compared to 2016. For an average individual from 2016, the TZ formed around day 265 (late September) at an age of 166 ( \pm 33 days) days, while it occurred around day 230 (mid-August) and at an age of 131 ( \pm 26 days) days in 2015. Individuals in 2016 had an average TL of $110 \mathrm{~mm}( \pm 18 \mathrm{~mm})$ while those from $2015 \mathrm{had}$ an average TL of $91 \mathrm{~mm}( \pm 15 \mathrm{~mm})$ when TZ formation started.

From February to June, the ambient temperatures increasingly approached the optimal growth temperatures for YOY WBC. The ambient temperatures started to exceed this length-based temperature threshold during the second half of July. The period of higher than optimum ambient temperatures continued until October and then temperatures dropped back below the optimum in November (Fig. 2b). The formation of the TZ corresponded to the period during which ambient temperatures were at their peak and exceeded the temperatures optimal for growth (Fig. 6a).

\section{Discussion}

\section{Precision and accuracy of micro-increment counting}

We found that micro-increments of juvenile WBC otoliths could be counted with high precision, but the accuracy of micro-increment counting (i.e., their relationship with age of the fish) was very low for cod that had lived through at least one winter. This makes micro-increment analysis appropriate for exploring life history of YOY cod, but likely inappropriate for making inferences about age and life history of older individuals.

Although no directional bias in the increment counts was observed, increment counts were less precise with increasing quality-flag (i.e., decreasing quality). Differences in the quality of the prepared otolith sections can stem from different reasons, e.g., natural variability in the visibility of otolith structures, possible unevenness of a subset of the prepared otolith sections, or the light source used may not have been bright enough to penetrate denser parts of some otoliths. However, the average uncertainty in daily increment counts of 10 days in this study was slightly lower than the 14, 15 and 13 days reported by Bolz and Lough (1988), Oeberst and Böttcher (1998) and Rehberg-Haas et al. (2012), respectively, though inter-study variation in methods used to evaluate uncertainty may have contributed to the differences reported.

The availability of age validated otolith material greatly improved our ability to assess the accuracy of the microincrement counts. The accuracy of micro-increment counts of the marked recaptures was surprisingly low even for short-term recaptures, and very low for cod that spent at least one winter period in liberty. For the only age- $1 \mathrm{cod}$ released in May (29.05.2015) and recaptured in September of the same year (25.09.2015), the days at liberty estimated from micro-increment counts (102) were close to the real days at liberty (119 days), whereas the total number of counted micro-increments (192) missed the composed age of 539 days by 347 days. This suggests that the periodicity of otolith increment deposition changes during the year. This was supported by the severe underestimation of the actual number of days between release and recapture in the microincrement counts of individuals marked prior to their first winter and recaptured in the next year. For WBC, the crucial 

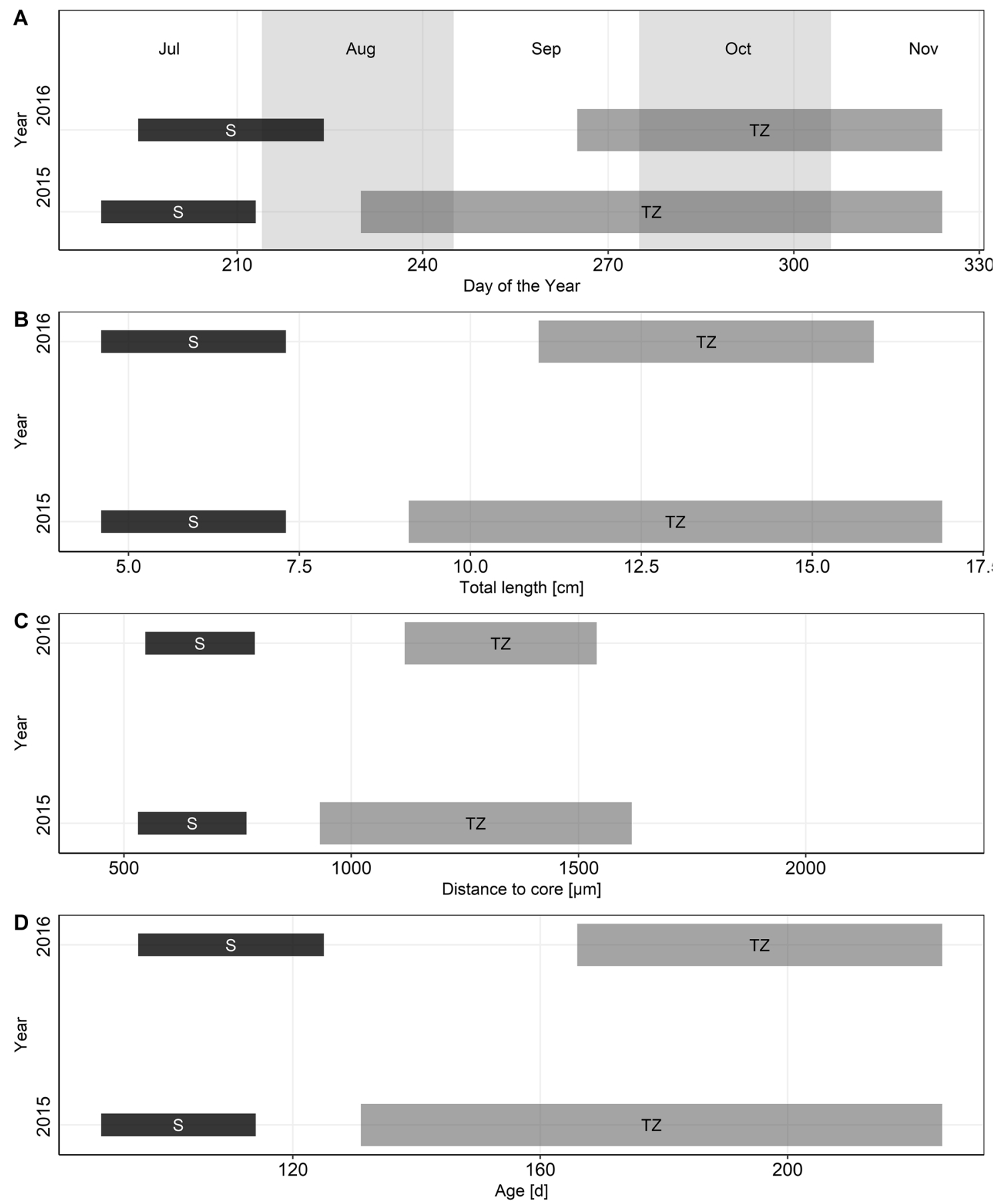

Fig. 6 Comparison of the timing and size at settlement and formation of the translucent zone (TZ) for juvenile WBC. Bars mark the period (average start to average end) during which the respective event occurs with $n=39$ and $n=51$ otoliths in 2015 and 2016, respectively.

period when increments do not form with a daily periodicity seems to be the winter season, as has also been reported for cod in the eastern Baltic Sea (Hüssy et al. 2010). The nondaily periodicity of increment formation, which was already observed during the first winter, may explain the apparent
Both events were compared to date (a), fish size (b), otolith size (c) and age (d). Black: period related to settlement; grey: formation of the TZ (observed otolith radius)

under-estimation of age of juvenile WBC estimated from micro-increments by Rehberg-Haas et al. (2012) detected by McQueen et al. (2019). Interestingly, otolith zones lacking visible micro-increments were not detected in the WBC otoliths analysed here, in contrast to the clear zones without 

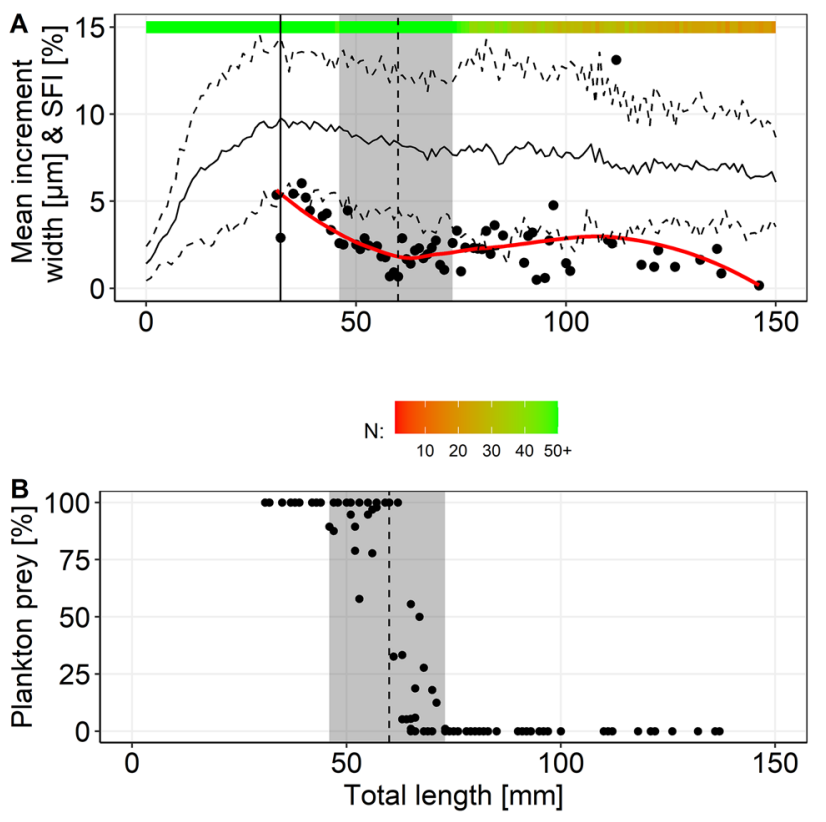

Fig. 7 a Combined information about estimated otolith increment width and stomach contents of juvenile WBC from 2016 only. Black horizontal lines: increment width $[\mu \mathrm{m}]($ mean (solid) \pm CI (dashed)); black dots: the relative stomach content of $n=110$ juvenile cod [\%]. Grey area: estimated period of settlement; dotted vertical line: length at which the prey shift to benthic food organisms was observed; solid line: TL at which increment widths were highest $(3 \mathrm{~cm})$; colored horizontal line: number of increments included in the mean increment width; red line: mean relative stomach content. b Relative diet share of planktonic prey (\%) in relation to size of $n=110$ juvenile WBC

visible increments reported in EBC otoliths (Hüssy et al. 2010). Some micro-increments could be counted in WBC otoliths from cod which had only been at liberty during the winter months (e.g., Fish IDs 1, 10 in Table 2), indicating that even during the winter period increments are formed, though with a non-daily periodicity.

Low agreement between number of counted otolith micro-increments and age of fish has also been reported for older individuals of several other fish species. The periodicity of otolith increments of wild Merluccius capensis, Merluccius paradoxus and Genypterus capensis gradually decreased (several days for 1 increment) after the first year with increasing age, and increment formation even stopped under physiological or environmental stress (Morales-Nin 1987). Large tuna (Thunnus obesus, Katsuwonus pelamis, and Thunnus albacares) in both the Indian and Atlantic Ocean could not be aged reliably using optical microscopes (Hallier et al. 2005; Sardenne et al. 2015) and micro-increment formation changed to a non-daily formation around an age of 300 days in wild ayu Plecoglossus altivelis (Tsukamoto and Kajihara 1987).

The reasons for cessation of mico-increment formation in EBC otoliths during winter are yet to be determined (Hüssy et al. 2010). The periodicity of formation of micro-increments in fish otoliths has been directly linked to photoperiod (Wright et al. 1992), temperature (Neat et al. 2008; Hüssy et al. 2010) and feeding levels (Bailey and Stehr 1988). It therefore seems likely that the conditions that Baltic cod experience in winter, namely short day lengths, cold temperatures, potentially reduced feeding opportunities and reduced evacuation speed, somehow disrupt the daily periodicity of micro-increment formation. We therefore conclude that some important assumptions for micro-increment analysis are only met during specific periods, which might be associated with the annual temperature and solar cycle. Increasing temperatures and increasing day-lengths seem to strengthen the link between increment formation and a daily periodicity as exemplified by the recaptured individual of category 2 (Supplementary Fig. S6). These results highlight the importance of age-validated material covering different intervals (days, weeks and months) and different seasons (at liberty during both summer and winter) for a critical evaluation of the interpretation of micro-increment counts.

Furthermore, one fish recaptured 5 days after tagging displayed the tetracycline band at the outermost edge of the otolith. Injected tetracycline is usually incorporated rapidly, often within $24 \mathrm{~h}$ (Meunier and Boivin 1974; Wild and Foreman 1980), but delayed incorporation over more than a single day is not uncommon and can span several increment time periods (e.g., in goldfish (Kobayashi et al. 1964) or starry flounder Platichthys stellatus (Campana and Neilson 1982)). The lack of visible micro-increments 5 days after tagging using standard microscope settings suggests that in certain individuals tetracycline injection may cause a posttagging disruption in micro-increment formation. Other species such as sparid fish and Atlantic tuna showed atypical behaviour for 2-7 days after tagging which sometimes even led to visible marks on the otolith (Lang and Buxton 1993; Hallier et al. 2005). While not being relevant for long-term experiments, this nevertheless adds a considerable bias to short-term results as investigated in this study, indicating that the accuracy of daily increment counts in this study may be higher for short-term recaptures than the results suggest.

\section{Hatch and settlement period of Western Baltic cod}

The peak hatch period of late March inferred from analysis of the otoliths from YOY cod in 2015 and 2016 overlaps with the spawning period of cod during March and April in SD 22, estimated for the years 1992-2005 (Bleil et al. 2009). Given the incubation period of cod eggs (Pepin et al. 1997), the individuals analysed in this study must have arisen from spawning that occurred early in the spawning season. The hatch dates estimated from another recent study on microstructure of WBC otoliths were much later than estimated here, with a peak hatch period of May and June reported for 
2008 and 2009 (Rehberg-Haas et al. 2012). These diverging results may indicate a gradual shift in spawning time of WBC, but may also be due to under-estimation of age of some otoliths in Rehberg-Haas et al. (2012) (see previous section). Two individuals in the present study were estimated to have hatched in summer (June and July), much later than all other sampled juveniles. It is possible that these belonged to the EBC stock, which spawn in summer (Bagge et al. 1994). We therefore conclude that the hatch dates estimated from the micro-structure of YOY WBC otoliths are reasonable, given the known spawning times of Baltic cod. This provides further evidence to support our conclusion that micro-increments can be assumed to form on a daily basis until the first winter.

The prey shift of cod from planktonic to benthic prey organisms observed here has also been reported in other studies (Lomond et al. 1998; Oeberst and Böttcher 1998), covering different regions ranging from Trinity Bay (Newfoundland) to the North Sea and Baltic Sea. The prey shift occurred at around $\sim 60 \mathrm{~mm}$ TL in all listed studies, indicating that the size during the prey shift is similar across different regions and decades. This supports our assumption that settlement of western Baltic cod juveniles in 2015 occurred at the same size as in 2016. However, data were not available to test this assumption, and directed studies would need to be conducted to confirm whether any inter-annual variability may be present. Since the SFI observed in this study decreased before the prey shift, it is reasonable to assume that growing energetic needs cause juvenile cod to change their diet, as was suggested by Oeberst and Böttcher (1998).

Previous studies stated that settlement of different cod stocks takes place at an age of 80-140 days (Bolz and Lough 1988; Oeberst and Böttcher 1998; Hüssy et al. 2003b) and in a size range from 40 to $100 \mathrm{~mm}$ (Oeberst and Böttcher 1998; Hüssy et al. 2003b; Gjøsæter and Danielssen 2011). Juvenile cod older than 125 days were caught predominantly using demersal fishing gear in previous studies (Oeberst and Böttcher 1998), indicating that settlement occurs simultaneously with the prey shift in different cod stocks. This latter settlement period is consistent with the age (89-124 days) and size (46-73 mm) of WBC during the prey shift, further strengthening evidence for the link between settlement and prey shift.

Reduced otolith opacity has been linked to periods of reduced food supply or starvation in other studies (Hüssy and Mosegaard 2004; Høie et al. 2008). This could explain the TZ check observed in Rehberg-Haas et al. (2012) and DECODE (2009) in relation to settlement. However, no obvious decrease or any other pattern in increment widths or otolith opacity was observed during the prey shift period in this study. The change from the pelagic to the demersal life phase likely comprises a transition period with a decreasing proportion of pelagic and an increasing proportion of benthic habitat use (Tupper and Boutilier 1995; Oeberst and Böttcher 1998). In line with these findings, Bolz and Lough (1988) concluded that settlement, taking place over an extended period, is unlikely to cause a metabolic disturbance which could lead to a visible check on the otolith. Only 4 out of 157 individuals in their study displayed a further check after the yolk-sac phase on the otoliths. However, these checks were not formed consistently and were considered related to individual physiological "traumata" such as diseases or injuries (Bolz and Lough 1988). We therefore conclude that analysis of otolith microstructure does not seem to be an appropriate method to determine timing of settlement of WBC, and alternative methods, such as stomach content analysis, are therefore more appropriate.

\section{TZ formation}

The present study independently and directly confirmed that only one TZ in WBC otoliths is formed in the first year, and that it is formed during the peak summer period. These findings are in line with recent age validation studies of cod from the same region (McQueen et al. 2019; Krumme et al. 2020). We can specify that the TZ formation in age- 0 cod coincided with the period when ambient water temperatures exceeded optimal water temperatures for growth of cod of this size $\left(\sim 17-19^{\circ} \mathrm{C}\right.$, calculated from Björnsson (2001)). TZ formation started later in 2016 compared to 2015, which is most likely related to the lower temperatures experienced by the trawled cod compared to the conspecifics caught in shallow-water pound nets. Stomach fullness indices (SFI) were low during settlement but increased once TZ formation started. TZ formation was therefore apparently unrelated to settlement or food level in YOY WBC.

Laboratory experiments with Atlantic cod have revealed decreasing otolith opacity with increasing temperatures (Neat et al. 2008). The same study found a positive relationship between temperature and increment width of daily micro-increments, with no relationship between somatic growth and increment widths. In contrast, temperature explained only $30 \%$ of the variation in increment widths of wild caught cod (Campana 1996), as was also the case with our data (Supplementary Table S4). Such seemingly contradictory results, e.g., whether ambient temperatures may or may not influence otolith opacity or increment width, were investigated by Fablet et al. (2011) and are probably related to the complex interactions of metabolic processes and environmental conditions. We therefore conclude that in the field, increment widths are probably not solely related to temperature, while the relationship between otolith opacity and temperature is more consistent. Additional analyses, ideally combining laboratory experiments with observed field data are required to definitively investigate the relationship between increment 
widths of juvenile WBC otoliths and biotic and abiotic factors, and confirm the suggested relationship between ambient temperatures and otolith opacity.

\section{Conclusion}

Micro-increments, when formed on a daily basis, may provide valuable insights into the timing of life-history events, the formation of otolith macro-structures used for routine aging, and growth rates of juveniles. In this study, we demonstrated the importance of validating ageing structures to avoid misleading results. We found that micro-increment counts increasingly underestimated the age of cod aged 1 and older, and micro-increments formed over the summer period more closely reflected a daily periodicity than increments formed over the winter. Therefore, some important assumptions for micro-increment analysis are apparently met only during specific seasons. Microincrement analysis did however provide realistic results when used to estimate the timing of previously studied life history events of YOY cod. We therefore recommend the use of microstructure analysis only for YOY WBC captured before their first winter. The analysis of otolith microstructure of such individuals is a promising method to investigate how variation in early life history may influence recruitment and year class strength of WBC.

Supplementary Information The online version contains supplementary material available at https://doi.org/10.1007/s00227-021-03834-x.

Acknowledgements We thank the fisher Erhard Pahlke and Uli Fröse for providing the samples of juvenile Baltic cod from their pound nets. We also thank the team from the University of Hamburg collecting juvenile cod with the vessel SEABULL and the staff from the Thünen Institute of Baltic Sea Fisheries in Rostock involved in data collection and processing. Suggestions of two anonymous reviewers helped to improve the manuscript.

Funding Open Access funding enabled and organized by Projekt DEAL.

Data availability The datasets generated and analyzed during the current study are available from the corresponding author on reasonable request.

Code availability Not applicable.

\section{Compliance with ethical standards}

Conflict of interest We have no conflicts of interest to disclose. The cod tagging experiment was conducted under the animal test permission of Schleswig-Holstein V 244-7224.121.9-6 (84-6/14).
Ethical approval The cod tagging experiment was conducted under the animal test permission of Schleswig-Holstein V 244-7224.121.9-6 $(84-6 / 14)$

Consent for publication All the authors have approved the contents of this paper and have agreed to the Marine Biology submission policies.

Open Access This article is licensed under a Creative Commons Attribution 4.0 International License, which permits use, sharing, adaptation, distribution and reproduction in any medium or format, as long as you give appropriate credit to the original author(s) and the source, provide a link to the Creative Commons licence, and indicate if changes were made. The images or other third party material in this article are included in the article's Creative Commons licence, unless indicated otherwise in a credit line to the material. If material is not included in the article's Creative Commons licence and your intended use is not permitted by statutory regulation or exceeds the permitted use, you will need to obtain permission directly from the copyright holder. To view a copy of this licence, visit http://creativecommons.org/licenses/by/4.0/.

\section{References}

Bagge O et al (1994) The Baltic cod. Dana. Springer, Berlin, pp 1-28 Bailey KM, Stehr CL (1988) The effects of feeding periodicity and ration on the rate of increment formation in otoliths of larval walleye pollock Theragra chalcogramma (pallas). J Exp Mar Biol Ecol 122(2):147-161. https://doi.org/10.1016/0022-0981(88)90181-5

Baumann H, Peck MA, Herrmann J-P (2005) Short-term decoupling of otolith and somatic growth induced by food level changes in postlarval Baltic sprat, Sprattus sprattus. Mar Freshw Res 56(5):539_ 547. https://doi.org/10.1071/MF04140

Beamish RJ, McFarlane GA (1983) The forgotten requirement for age validation in fisheries biology. Trans Am Fish Soc 112(6):735743. https://doi.org/10.1577/1548-8659(1983)112\%3c735:TFRFA $\mathrm{V} \% 3 \mathrm{e} 2.0 . \mathrm{CO} ; 2$

Beamish RJ, McFarlane GA (1987) Current trends in age determination methodology. Age and growth of fish. Iowa State University Press, Iowa City, pp 15-42

Björnsson B (2001) Optimal temperature for growth and feed conversion of immature cod (Gadus morhua L.). ICES J Mar Sci 58(1):29-38. https://doi.org/10.1006/jmsc.2000.0986

Bleil M, Oeberst R, Urrutia P (2009) Seasonal maturity development of Baltic cod in different spawning areas: importance of the Arkona Sea for the summer spawning stock. J Appl Ichthyol 25(1):10-17. https://doi.org/10.1111/j.1439-0426.2008.01172.x

Bolle LJ et al (2004) Growth changes in plaice, cod, haddock and saithe in the North Sea: a comparison of (post-)medieval and present-day growth rates based on otolith measurements. J Sea Res. 51(3):313-328. https://doi.org/10.1016/j.seares.2004.01.001 (Proceedings of the fifth international symposium on flatfish ecology, part II)

Bolz GR, Lough RG (1988) Growth through the first six months of Atlantic cod, Gadus morhua, and haddock, Melanogrammus aeglefinus, based on daily otolith increments. Fish Bull 86(2):223-235

Brander KM (2005) Spawning and life history information for north Atlantic cod stocks. ICES Cooperative Research Report. http:// www.vliz.be/en/imis? module $=$ ref $\&$ refid $=74606 \&$ printversi on $=1 \&$ dropIMIStitle $=1$ Accessed 30 March 2020

Campana SE (1996) Year-class strength and growth rate in young Atlantic cod Gadus morhua. Mar Ecol Prog Ser 135:21-26. https ://doi.org/10.3354/meps135021 
Campana SE (2001) Accuracy, precision and quality control in age determination, including a review of the use and abuse of age validation methods. J Fish Biol 59(2):197-242. https://doi. org/10.1111/j.1095-8649.2001.tb00127.x

Campana SE (2011) Otolith microstructure of three larval gadids in the Gulf of Maine, with inferences on early life history. Can J Zool 67:1401-1410. https://doi.org/10.1139/z89-199

Campana SE, Moksness E (1991) Accuracy and precision of age and hatch date estimates from otolith microstructure examination. ICES J Mar Sci 48(3):303-316. https://doi.org/10.1093/icesj $\mathrm{ms} / 48.3 .303$

Campana SE, Neilson JD (1982) Daily growth increments in otoliths of starry flounder (Platichthys stellatus) and the influence of some environmental variables in their production. Can J Fish Aquat Sci 39(7):937-942. https://doi.org/10.1139/f82-127

Campana S, Neilson JD (1985) Microstructure of fish otoliths. Can J Fish Aquat Sci 42:1014-1032. https://doi.org/10.1139/f85-127

DECODE (2009) Improved methodology for baltic COD age estimation. Final project report. European Commission Studies; Pilot Projects for Carrying out the Common Fisheries Policy Contract no. FISH/2006/15

Delaney (A) 2007 Profiling of small-scale fishing communities in the Baltic Sea: Study requested by the european commission. IFMInnovative Fisheries Management. https://vbn.aau.dk/en/publi cations/profiling-of-small-scale-fishing-communities-in-the-balti c-sea-st. Accessed 4 March 2020

Fablet R et al (2011) Shedding light on fish otolith biomineralization using a bioenergetic approach. PLoS ONE 6(11):e27055. https:// doi.org/10.1371/journal.pone. 0027055

Folkvord A et al (2000) Growth-dependent age estimation in herring (Clupea harengus L.) larvae. Fish Res 46(1):91-103. https://doi. org/10.1016/S0165-7836(00)00136-3

Geffen AJ (1995) Growth and otolith microstructure of cod (Gadus morhua L.) larvae. J Plankton Res 17(4):783-800. https://doi. org/10.1093/plankt/17.4.783

Gjøsæter J, Danielssen DS (2011) Age, growth and otolith annulus formation of cod (Gadus morhua) in the Risør area on the norwegian skagerrak coast during 1986-1996. Mar Biol Res 7(3):281-288. https://doi.org/10.1080/17451000.2010.492225

Hallier JP et al (2005) Growth of bigeye tuna (Thunnus obesus) in the eastern Atlantic ocean from tagging-recapture data and otolith readings. Col Vol Sci Pap ICCAT 57(1):181-194

Høie $\mathrm{H}$ et al (2008) Restricted fish feeding reduces cod otolith opacity. J Appl Ichthyol 24(2):138-143. https://doi.org/10.111 $1 /$ j.1439-0426.2007.01014.x

Hüssy K (2010) Why is age determination of Baltic cod (Gadus morhua) so difficult? ICES J Mar Sci 67(6):1198-1205. https:// doi.org/10.1093/icesjms/fsq023

Hüssy K, Mosegaard H (2004) Atlantic cod (Gadus morhua) growth and otolith accretion characteristics modelled in a bioenergetics context. Can J Fish Aquat Sci 61(6):1021-1031. https://doi. org/10.1139/f04-038

Hüssy K et al (2003a) Factors determining variations in otolith microincrement width of demersal juvenile Baltic cod Gadus morhua. Mar Ecol Prog Ser 258:243-251

Hüssy K et al (2003b) Using otolith microstructure to analyse growth of juvenile Baltic cod Gadus morhua. Mar Ecol Prog Ser 258:233-241

Hüssy K et al (2010) The use of otolith microstructure to estimate age in adult Atlantic cod Gadus morhua. J Fish Biol 76(7):1640-1654. https://doi.org/10.1111/j.1095-8649.2010.02602.x/full

Huwer B (2009) The recruitment process in Baltic cod: Spatiotemporal variation in starvation and predation during early life stages with special consideration of the invasive ctenophore Mnemiopsis leidyi. PhD thesis. Technical University of Denmark (Danmarks Tekniske Universitet), National Institute of
Aquatic ResourcesInstitut for Akvatiske Ressourcer, Section for Population Ecology; GeneticsSektion for Populations $\varnothing$ kologi oggenetik. http://orbit.dtu.dk/fedora/objects/orbit:81449/datastream s/file_4006987/content. Accessed 7 Sep 2017

ICES (2014) ICES dataset on ocean hydrography. The international Council for the Exploration of the Sea, Copenhagen. https://ocean .ices.dk/HydChem/HydChem.aspx?plot=yes. Accessed 10 Nov 2020

ICES (2020) Cod (Gadus morhua) in subdivisions 22:24, western Baltic stock (western Baltic Sea). ICES, London. https://doi. org/10.17895/ICES.ADVICE.5942

Kalish JM et al (1995) Glossary for otolith studies. Recent developments in fish otolith research. The Belle Baruch Library of Marine Science. University of South Carolina, Columbia, pp 723-729

Kobayashi S et al (1964) Calcification in fish and shell-fish I. Tetracycline labelling patterns on scale, centrum and otolith in young goldfish. Bull Jap Soc Sci Fish 30(1):6-13

Krumme U et al (2020) Age validation of age 0-3 wild cod (Gadus morhua) in the western Baltic Sea through mark-recapture and tetracycline marking of otoliths. Mar Ecol Prog Ser. https://doi. org/10.3354/meps 13380

Kurlansky M (1997) Cod: a biography of the fish that changed the world. Walker Publishing Company Inc, New York

Lang JB, Buxton CD (1993) Validation of age estimates in sparid fish using flubrochrome marking. Afr J Mar Sci 13(1):195-203. https://doi.org/10.2989/025776193784287284

Lang KL et al (1996) The use of otolith microstructure in resolving issues of first year growth and spawning seasonality of white hake, Urophycis tenuis, in the gulf of Maine-Georges bank region scientific publications office. NOAA Sci Publ Off 94:170-175

Link J et al (2008) Trophic role of Atlantic cod in the ecosystem. Fish Fish 10:58-87. https://doi.org/10.1111/j.1467-2979.2008.00295.x

Lomond TM, Schneider DC, Methven DA (1998) 'Transition from pelagic to benthic prey for age group 0-1 Atlantic cod, Gadus morhua. Fish Bull 96:908-911

McQueen K, Hrabowski J, Krumme U (2019) Age validation of juvenile cod in the western Baltic Sea. ICES J Mar Sci 76(2):430-441. https://doi.org/10.1093/icesjms/fsy175

Meunier F, Boivin G (1974) Divers aspects de la fixation du chlorhydrate de tetracycline sur les tissus squelettiques de quelques teleosteens. Bull Soc Zool Fr 99:495-504

Morales-Nin BYO (1987) The influence of environmental factors on microstructure of otoliths of three demersal fish species caught off Namibia. Afr J Mar Sci 5(1):255-262. https://doi. org/10.2989/025776187784522207

Narimatsij Y et al (2007) Somatic growth and otolith microstructure of larval and juvenile pacific cod Gadus macrocephalus. Fish Sci 73(6):1257-1264. https://doi.org/10.111 1/j.1444-2906.2007.01463.x

Neat FC, Wright PJ, Fryer RJ (2008) Temperature effects on otolith pattern formation in Atlantic cod Gadus morhua. J Fish Biol 73(10):2527-2541. https://doi.org/10.111 1/j.1095-8649.2008.02107.x

Oeberst R, Böttcher U (1998) Development of juvenile Baltic cod described with meristic, morphometric and sagitta otolith parameters. ICES CM 1998, 200, p 30. http://www.ices.dk/sites/pub/ CM\%20Doccuments/1998/CC/CC1598.pdf. Accessed 7 Sep 2017

Panella G (1971) Fish otoliths: daily growth layers and periodical patterns. Science 173:1124-1127

Pepin P, Orr DC, Anderson JT (1997) Time to hatch and larval size in relation to temperature and egg size in Atlantic cod (Gadus morhua). Can J Fish Aquat Sci 54(S1):2-10. https://doi. org/10.1139/f96-154 
R CoreTeam 2020 R: a language and environment for statistical computing. Vienna, Austria: R Foundation for Statistical Computing. https://www.R-project.org/.

Ralston S, Williams HA (1989) Numerical integration of daily growth increments: an efficient means of ageing tropical fishes for stock assessment. Fish Bull 87(1):1-16

Rehberg-Haas S et al (2012) Otolith microstructure analysis to resolve seasonal patterns of hatching and settlement in western Baltic cod. ICES J Mar Sci 69(8):1347-1356

Sardenne F et al (2015) Determining the age of tropical tunas in the Indian ocean from otolith microstructures. Fish Res 163:44-57. https://doi.org/10.1016/j.fishres.2014.03.008

Stevenson DK, Campana SE (1992) Otolith microstructure examination and analysis. Can Spec Publ Fish Aquat Sci 117:293

Stiasny MH et al (2016) 'Ocean acidification effects on Atlantic cod larval survival and recruitment to the fished population. PLoS ONE 11(8):e0155448. https://doi.org/10.1371/journal.pone.01554 48

Stötera S, Krumme U (2016) Use of otolith quality flags to assess distributional dynamics in Baltic cod stocks. Mar Freshw Res 67(7):980-991. https://doi.org/10.1071/MF15048

Strehlow HV et al (2012) Cod catches taken by the German recreational fishery in the Western Baltic Sea, 2005-2010: implications for stock assessment and management. ICES J Mar Sci 69(10):1769-1780

Thurow F (1963) Dorschmarkierungen in der Westlichen Ostsee. Informationen für die Fischwirtschaft 10(1): 12-17. http://aquacomm. fcla.edu/8279. Accessed 24 March 2020

Tsukamoto K, Kajihara T (1987) 'Age determination of ayu with otolith. Nippon Suisan Gakkai Shi 53(11):1985-1997. https://doi. org/10.2331/suisan.53.1985
Tupper M, Boutilier R (1995) Size and priority at settlement determine growth and competitive success of newly settled Atlantic cod. Mar Ecol Prog Ser 118:295-300. https://doi.org/10.3354/meps118295

Vitale F, Clausen LW, Ní Chonchúir G (2019) Handbook of fish age estimation protocols and validation methods Report. Int Council Explor Sea (ICES). https://doi.org/10.17895/ices.pub.5221

Voss R et al (2019) Ecological-economic sustainability of the Baltic cod fisheries under ocean warming and acidification. $\mathbf{J}$ Environ Manag 238:110-118. https://doi.org/10.1016/j.jenvm an.2019.02.105

Waldron ME, Kerstan M (2001) Age validation in horse mackerel (Trachurus trachurus) otoliths. ICES J Mar Sci 58(4):806-813. https ://doi.org/10.1006/jmsc.2001.1071

Wild A and Foreman TJ (1980) The relationship between otolith increments and time for yellowfin and Skipjack Tuna marked with tetracycline. http://aquaticcommons.org/3372/1/Vol._17_no._7.pdf. Accessed 23 Oct 2019

Wright PJ, Metcalfe NB, Thorpe JE (1990) Otolith and somatic growth rates in Atlantic salmon parr, Salmo salar L.: evidence against coupling. J Fish Biol 36(2):241-249. https://doi. org/10.1111/j.1095-8649.1990.tb05599.x

Wright PJ, Talbot C, Thorpe JE (1992) Otolith calcification in Atlantic salmon parr, Salmo salar L. and its relation to photoperiod and calcium metabolism. J Fish Biol 40(5):779-790. https://doi. org/10.1111/j.1095-8649.1992.tb02624.x

Publisher's Note Springer Nature remains neutral with regard to jurisdictional claims in published maps and institutional affiliations. 